\title{
Characterization of Rheological Behavior of Non- Newtonian Oil Well Drilling Muds at Low Shear Rates
}

\author{
Dr. Shallal N. Mahdi \\ AL-Farabi University College \\ Email: Aldelaimi.shallal@yahoo.com \\ DOI: $10.31364 /$ SCIRJ/v8.i10.2020.P1020815 \\ http://dx.doi.org/10.31364/SCIRJ/v8.i10.2020.P1020815
}

\begin{abstract}
Non -Newtonian Drilling muds are liquid fluids, made practically from some sort of chemically active, mica like hydrated sedimentary clays of origin from the Cretaceous age, called Sodium Montmorillonite, which may mix with other additives to form oil well drilling muds.

Oil well drilling muds are slim suspension systems, used to hold and lift drilling bit excavated soil and rock cuttings up wellbore from down hole to surface separation and treating systems. Those flaky suspensions can generate groups and or series of chemical structures once mixed with water. These structures will be strong and firm according to the concentration of the components of the suspension, also, to the rest or static conditions which can be measured by a particular rotary sensing apparatuses, called rheometrs.

Agitating or stirring muds will subject these structures to be sheared from one side and to intermolecular friction movement, where the first is called gel breaking resisting forces and the viscosity resistance forces to flow.

This work is dealing with the Non-Newtonian soft dynamic conditions of oil well drilling muds, that means Rheological behavior at low shear rates of muds, which is more complex than water Newtonian dynamic conditions, that complexity of fluids increases with other additives due to the variant nature of constituents.

For more comprehension to the academic pandemic contravention of this issue, many experiments were performed to test for gelation and dynamic behavior at low shear rates, showed that pure bentonites suspension, also pure polymers suspension from the type of starch and carboximethyle cellulose(CMC) and their combinations, have shown that the components composition which give their initial proportional complex influences to those suspensions respectively.

These behaviors were plotted on both linear Cartesian coordinate $\mathrm{s}$ and logarithmic coordinates, where deep analysis was made for both gelation and fluid ability behaviors with many other results were also tiered out.
\end{abstract}

Key words: Drilling Muds Rheology, Non-Newtonian Fluids, Oil well Drilling, Bentonites-Polymer Suspensions.

\section{1- Objective:}

Although complex Non-Newtonian drilling muds are long under study, but still under pandemic controversial complexity and not well solved issue. This work is another attempt trying to shed more light on the rheological behavior of basic types of these muds, particularly under critical, low shear rates, say bellow 200 (1/second) $1 / \mathrm{s}$ or below, till fluid at rest or no motion state. Actually, this study is concerned with tension pressure on the mud fluid, say " stress taw $\mathrm{T}=\mathrm{y}$ " at critical low shear oryis = zero or not. In other words to study the gelation and fluidizing behavior near stop shearing mud, where scientists are disagreeing if the stress value goes to zero or not at shear rate, $\mathrm{Lambda}=\mathrm{x}=0$.In other words, it is trying to put an end to the long un finished continuous controversy, at least from the academic point of view.

\section{2- Introduction:}

One of benefits of use of mud in oil well drilling is to transform solids and cuttings produced by the drilling bit to the surface separation and treatment tanks, that by suspending and lifting up these cuttings on board of microscopic chemically clayed series of sheath structures of mud.

This mud suspensions are chemically active to make these complex series of structures at low agitation or circulation of mud in the well, with more efficiency at fluid rest or no motion no circulation, keeping cuttings not to drop back down hole, where this is going to be discussed in more details in the theoretical section.

The oil industry, particularly drilling people of oil wells took care cleaning wells for economic and security measures and reasons, so they are choosing the best mud compositional components from clays and starch and other additives, like caustic soda, Sodium 
carbonates, lignosulphonates and others according to efficient mud requirements against drilled formations. In our case we remind again we used simple, basic mud suspensions.

Mud engineers and mud testers on drilling rigs, have their own methods of measuring and controlling specifications and characterstical properties of muds, like weight, viscosity, gelling pressure, alkalinity( $\mathrm{Ph})$, filtration, mud cake, rheological behavior and others.

2-1:History of the problem: Better cuttings lifting capacity at low pressure of mud circulation is still one of the targets of concerned operational and designers of drilling programs, also researchers and academic institutes and colleges.

In the year1922, Bingham had described the rheological behavior of simple bentonites suspensions, which is a linear relationship between pressure and circulation rate, which took his name later on. In the laboratory, the well is simulated by a concentric two small cylinders, the interior is rotatable to measure stress and rate of shear, which is called a rheometrs.

Ostwald in 1926, had introduced his power law to describe stress-strain relationship of the starch and polymer suspensions. Many other suspension types in the world industry were treated similarly and many rheological laws were introduced later on, Casson law, Hershel-Bukly law and others for that of paints industry, waxes, plastics, biobentonites industries and others.

2-2 :Tests performed: Many tests were made for the characterizing of rheology of simple suspensions of bentonites, carboxylmethyl-cellulose CMC and combination groups as follows:

1) Bentonites suspension group of 7 tests for: 40,50,60, 70, 80, 90, and $100 \mathrm{kgm}$ bentonites $/ \mathrm{m} 3$ fresh water.

2) CMC suspensions group of 8 tests for: $0.5,1,2,3,4,5,6$ and $7 \mathrm{kgm} \mathrm{CMC} / \mathrm{m} 3$ of water suspensions.

3) One combination group of basic $50 \mathrm{kgm}$ bentonites with: 1, 2, 3, 4, 5, 6, and $7 \mathrm{kgm}$ of CMC respectively.

4)One combination group of $3 \mathrm{kgm}$ CMC with:40, 50, 60, 70 and $80 \mathrm{kgm}$ bentonites.

5) Other group of tests for viscosity, zero gel and turbulent flow dynamics by 1,3 , and $5 \mathrm{kgm}$ of neat CMC.

6) Another group to test similarly with: $1 \mathrm{~km} \mathrm{CMC} / \mathrm{m} 3$ water, $40 \mathrm{kgm}$ bentonites $/ \mathrm{m} 3$ water, $100 \mathrm{kgm}$ bentonites $/ \mathrm{m} 3 \mathrm{water}, 7 \mathrm{kgm}$ $\mathrm{CMC} / \mathrm{m} 3$ water and combination of $50 \mathrm{kgm}$ bentonites plus $5 \mathrm{kgm} / \mathrm{m} 3$ water.

7) Gelling test of suspension of $50 \mathrm{kgm}$ bentonites plus $3 \mathrm{kgm} \mathrm{CMC} / \mathrm{m} 3$ water after $0,1,5$ and 10 minutes time of rest.

8) One test for applicability or matching of power law and Bingham law to rheological behavior to $3 \mathrm{~km}$ CMC suspension and $(50 \mathrm{kgm}+3 \mathrm{kgm} \mathrm{CMC}) / \mathrm{m} 3$ water suspensions respectively.

\section{3-Theory:}

3-1:Theory of suspensions:

Bentonites and CMC crystalline materials are water super adsorbing substances, they appear as flakes and cords under microscope when they are dry. The flakes and cords could buff soon, when hydrated or mixed with water..

Figures 1a,1b and 1c show bentonites material under microscope, bentonites chemical bonded sheets and sketch of unit cell of CMC .Chemically the attractive cationic charges of Oxygen, Hydrogen, Carbone and other elements of the hydrated(H2O) component play their roles by bounding molecules of substance to build their characterstical structures, which influencing both the gelation and viscosifing the suspensions, mentioning that accelerated agitation and its duration are determinates factors in increasing numbers of dispersed cells, noting that the chemical formulas of mixed suspension of bentonites clay is $(($ $0.33 \mathrm{Na}(\mathrm{AL} 1.67 \mathrm{Mg} .33 \mathrm{O} 3$ ). $4 \mathrm{Si} \mathrm{O} 2$. $\mathrm{H} 2 \mathrm{O})$ ), for CMC Sodium type is (( C8 H15 Na O8 )) or ( C4H8) to any number $\mathrm{n}$ of cells, and for water is (( H2 O)). See fig $(1 \mathrm{a}, 1 \mathrm{~b}, 1 \mathrm{c})$ in below.

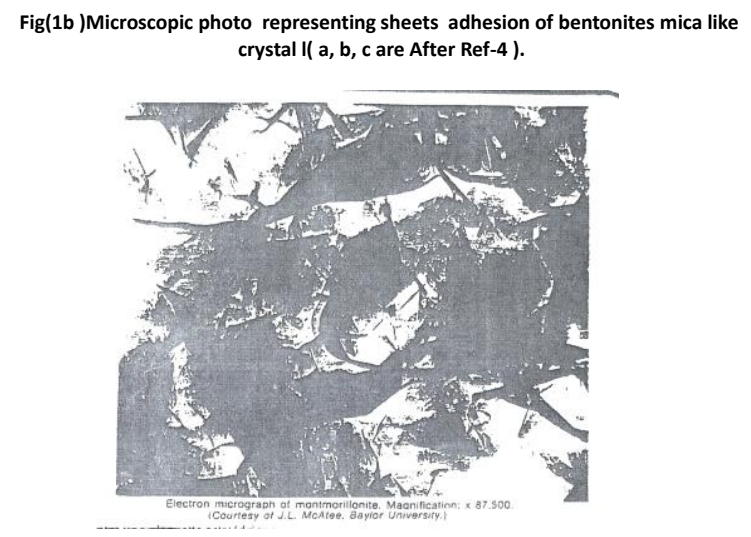

Fig(1a)Schematic diagram representing bonding between sheets of bentonites mica like crystal( a, b, c are After Ref-4)

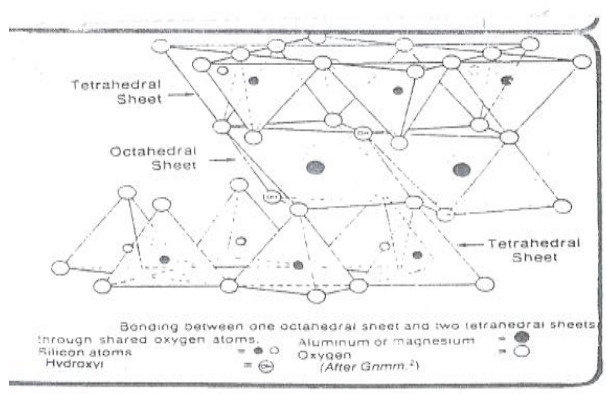



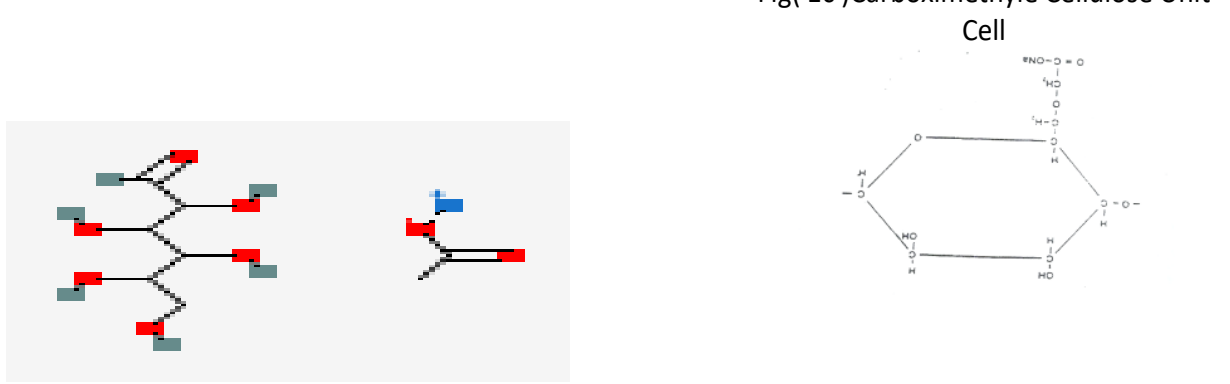

Infield our practice had showed that, drilling mud suspensions may dispersed in many forms or systems according to the drilling conditions, they may have the scattered sheets dispersion, which is the best, where mud has low gel but medium viscosity. Other system are like flocculated system, where it is characterized by high gel and high viscosity, so it must be treated to get first system. Another system is like agglomerated sheets of bentonites which give low viscosity and mid gel, which also better to treat it for the better.

3-2: Theory of rheological behavior measurement: We agreed that, rheometrs are simulating the oil well, more precisely the pipe and the annulus of the well. The electronic sensor of the rheometr can be designed to take measurement reading at anytime or at selected time readings by the interior cylinder as the resistance or spring is exposed to force as analogue to stator or well bore ( as the exterior cylinder or the rotor accelerates rotating as a drill pipe move in a well bore, the stress on spring is analogue to the force and the extension of it or resistance is analogue to the strain.

The fluid or the mud is moving as between two plackets ( if linear) for example or radial movement or any, where the rotation speed sensor and the pressure (stress) are taking their instructed sequential readings. By that we have read values for shear stress and rates at designed units, where in our case are the Pascal $(\mathrm{Pa})$, which is of $(10$ to power -5 of the Bar $)$ and the time which is a fraction of second, (1/second) or (1/s).

\section{3-3: Theory of mathematical rheological behaviors:}

Here we consider the most four scientifically popular mathematical models describing drilling mud rheological behaviors(stressstrain relationship), but only two are the most distinguished laws. The four are represented for the stress and strain by the $y$ and $x$ coordinates as follows:

1- Newtonian law, which is a striate line passing from origin of the cross plot, having a slope of one for water for example. $y=u x$ , where $\mathrm{y}$ is stress in Pascal-pa, $\mathrm{u}$ is viscosity(centipoises-cp)either plastic or apparent and $\mathrm{x}$ is shear rate in $1 / \mathrm{s}$.

2- Bingham Non-Newtonian linear having stress value passing above zero and a characteristic slope.

$\mathrm{y}=\mathrm{y} 0+\mathrm{ux}$, where $\mathrm{y} 0$ is initial gel strength, in Pascal pa, noting that $\mathrm{y} 0$ is extrapolated value on the y or stress coordinate, sometimes its real intercept is called true yield or stress value.

3- Ostwald Non-Newtonian or power law model having curved convex line, described some times as pseudplastic behavior. $\mathrm{y}=\mathrm{k}$ $\mathrm{x}$ (powered ton), where $\mathrm{k}$ is consistency index, $\mathrm{n}$ is rheological behavior index .

4- Non-Newtonian Hershil-Bukley law model, $y=y 0+k x$ (powered to $n$ ), noting that $y 0$ is mostly extrapolated value even in this model.

We mention that this relation may describe partially or totally of the velocity of the span of mud flow.

\section{4- Matching of rheological behavior of obtained rheograms of tested suspensions:}

One of the most important objective of this work is to check for the behavior of stress-strain relationship at as low as possible, so the Hauk rheometr was programmed at 2,3 (1/s) value of shear rate, see fig(3) increasing to 200(1/s) our concern and above for other objectives beyond the span of this study.

This in order to check if the influence of gelation before fluid movement and both including the viscosity influence are where to draw straight line or curved lines to describe the stress-strain behavior at that span of rate by the following subparagraphs and related figures.

4-1:Study of the thin and the thick for each class and combination:

In fig(3), we have two suspensions of bentonites, two of CMC and one moderate mixed concentration.

One can see the net difference between bentonites behaviors, which drop verse zero linearly (plastic)

before

curving(pseudo plastic) then another linearity in higher shear rate till perhaps turbulent flow. For the CMC and the combination, the CMC influence is clear on the suspensions, they are about to catch flow from very low or low values of stress- in the zero vicinity-or low yield at low shearing values. We have to say that in fig(4) the behavior is so net and the Ostwald behavior is dominant. 
Fig( 3 ) Rheology Behavior of Variant Suspensions at
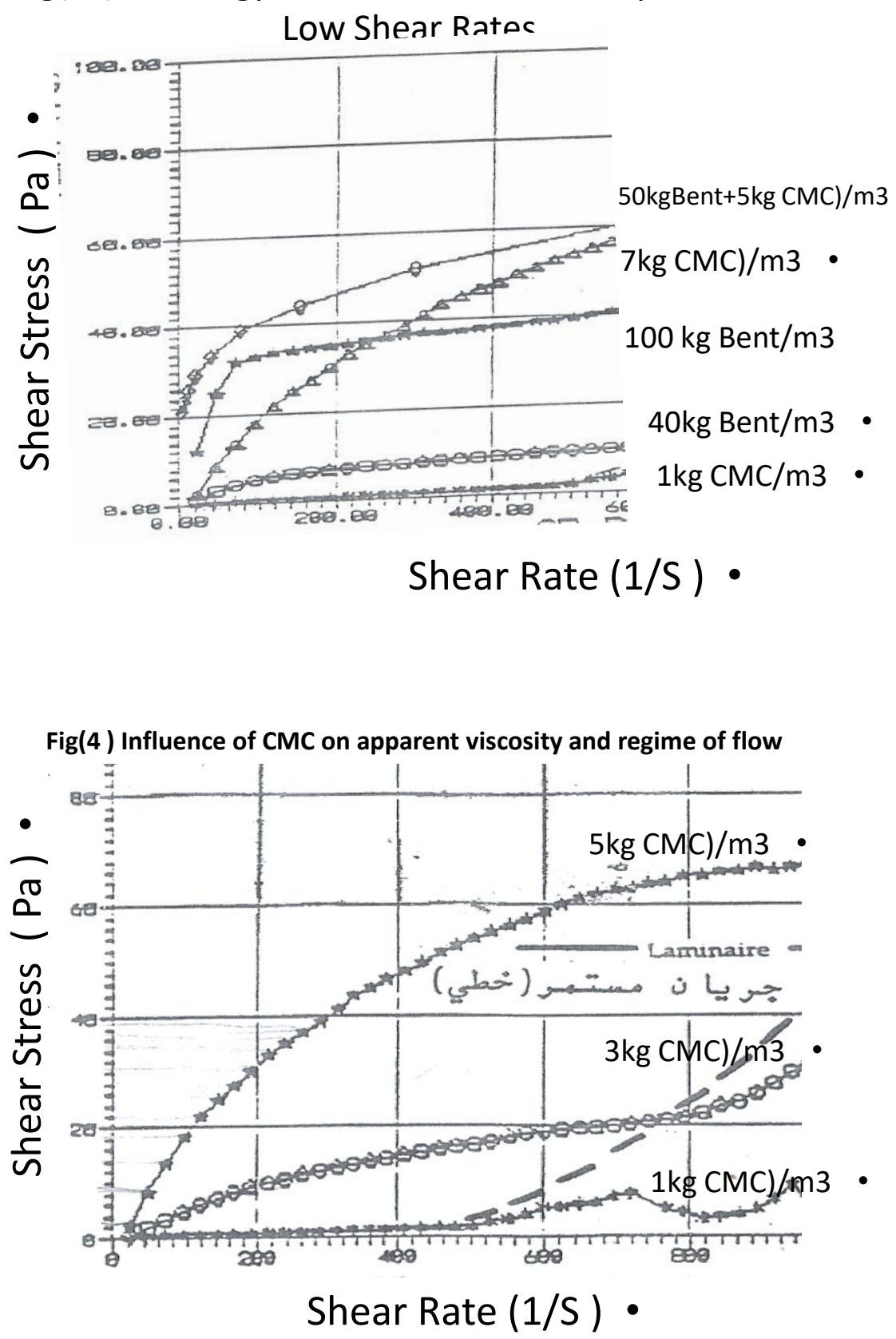

4-2:Study of the gelation timeon stress - strain in the zone of 200(1/s)rates:

A suspension of 50 (kgBent+3kg CMC) /m3 water showed the mark: In fig(5), It is clear that pressure curves are showing their departure from zero stress as starting from very low shear rates, but accelerating increasing, resisting gel, till maximums, then circulating breaking the gel, but not all, leaving some( structures ) strongly after circulation, but dropping gently with time of rest, which is explained by the gabs of stored energy as between curves of times of rests, which is exactly what happen when rig pumps start pumping mud after certain stopping circulating for any reason. Thus the importance of knowing the situation and being aware of it, by engineers and drillers is very necessary. 


\section{ظةFig(5) Evolution of Thixotropy at different rest times of tests for a suspension of $50(\mathrm{kgBent}+3 \mathrm{CMc}) / \mathrm{m} 3$ water.}

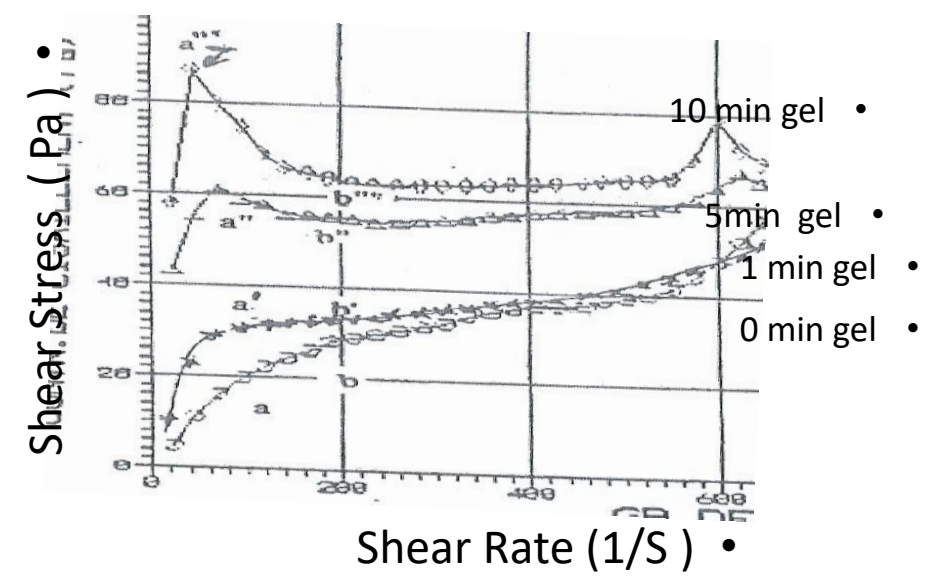

4-3: The gentle influence of consistency and fluidity index: As in real fields drilling muds, the CMC is always Used in second holes and in the production holes, the influence on the rheology curves is showing dominant pseudo-plastic behavior, from low shear rates and higher till the transitional or turbulence flow regime. It can be divided to sub-sections of linear(1), pseudo-plastic(2) and thirdly to plastic flow, In terms of gelation it characterized by low gel and low viscosity suspensions. See fig $(6 b)$.

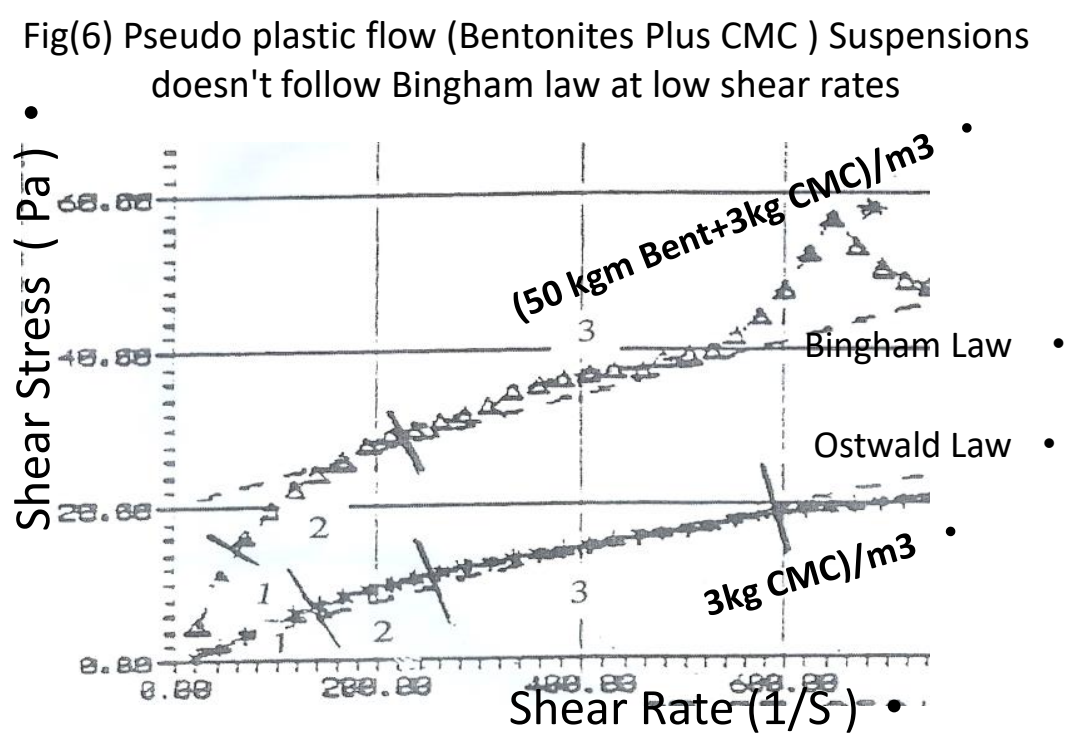

4-4: What other indications can be extracted from the log-log data presentation:

It appeared that the rheological curves of two groups of four cases of suspensions are either concaved in the case of pure bentonites (fig(7)) as example, or strait lines in the suspensions of pure CMC.

In the other two groups of mixed combinations, both groups of suspensions had showed concaved lines of behavior,(fig(8)) as example. One can notice that sensors didn't recorded measurements in the case of only bentonites suspensions, while they did in the case of mixed suspensions(figs(7 and 8 )), also noting that the separation of low shear rates and low concentrations of CMC not following totally Bingham law. 
Fig(7) Rheology by Log-Log scales presentation of different Bentonites suspensions

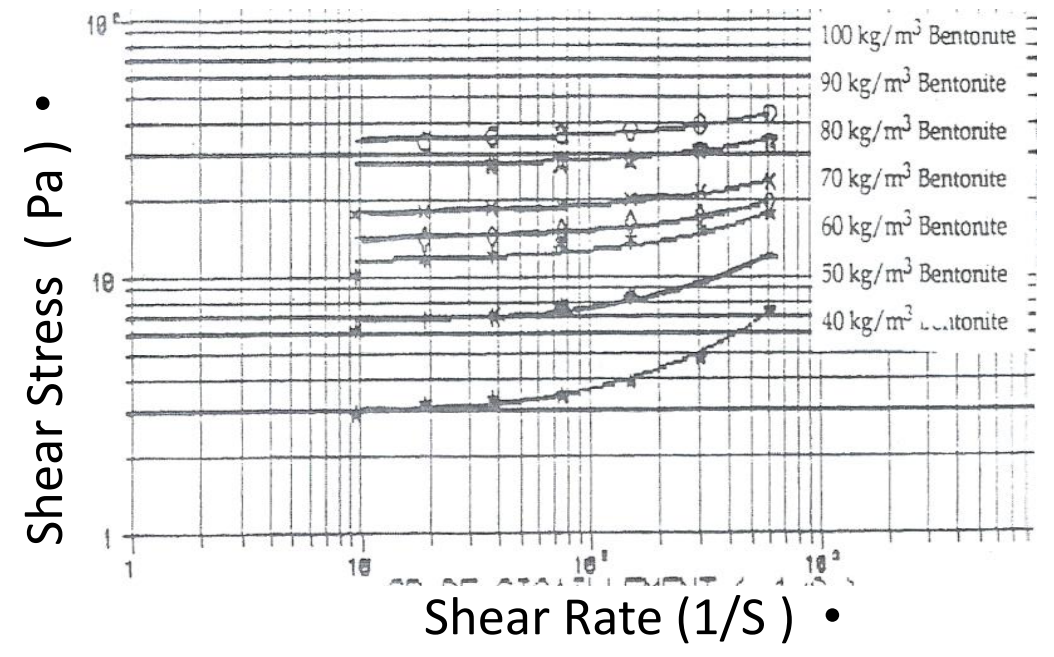

\section{Fig(8) Rheology by Log-Log scales presentation of different $\mathrm{CMC}$ suspensions with basic $50 \mathrm{gm} /$ litter}

\section{Bentonites.}

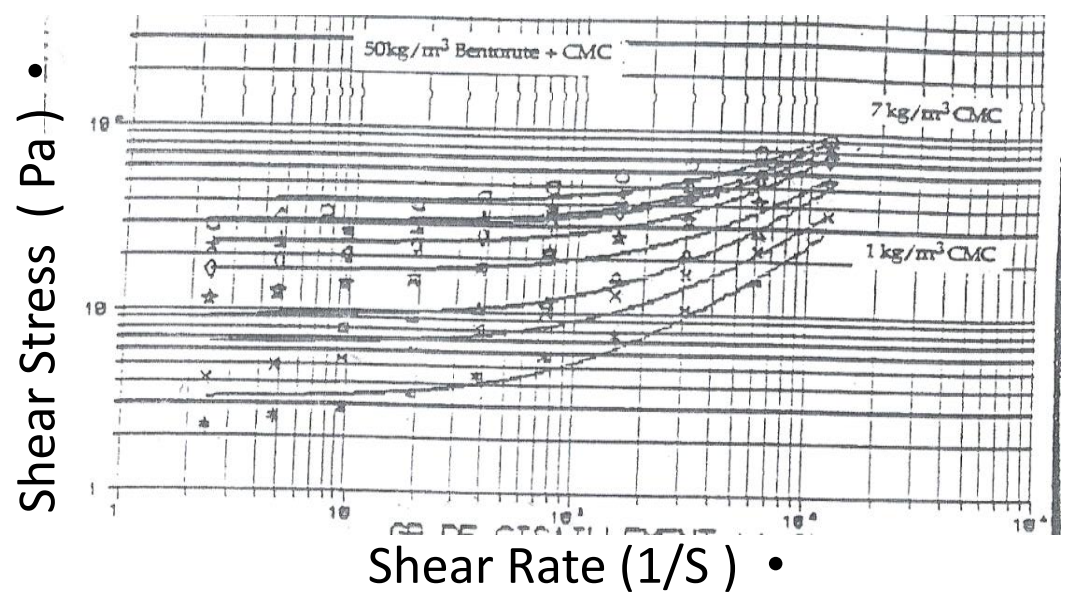

\section{5- Results and advices :}

We have discussed interiorly the theory of basic suspensions of bentonites, polymer CMC and combinations, which is the mostly used in normal drilling areasif we exclude the only clay mud type suspensions

The objective of any mud type of the mixed form of drilling mud program is to guarantee usable viscosity and useful gel, beside other mud characteristics like weight, alkalinity, oil content and others. This to support fluid velocity for hydraulic calculations. The gelation activity is controlled by the intensity of the cationic charges of the suspensions to make accelerated, slow from one side and strong or weak from the other side, where only accelerate- weak characterized gels are mostly preferable in practice and to some extent the strong- slow types of bonding gel.

The other side of gel property is it strong enough at zero strain ot no motion, or high but so weak to be broken at low or short strain, that to ease circulation of mud in low pressures in practice, also not make singularities in numerical solutions of velocity calculation for hydraulic programming.

In this work we mark well the three zones or stages of influence of ge: the first, which is strong but weak at the low shear rates, followed by steep pseudo-plastic or even plastic (according to bentonites concentration), then followed by the transitional or turbulent high shear rate circulation. 
In this work we mark again the importance of CMC fibers, which by hydration act to connect well by binding bentonites flakes with others and to make complex structures, which are strong enough to hold cuttings, but weak against pressures or stresses of shear.In the same time to keep the viscosity as the predominant factor of velocity resistance for mud circulation.

One more result of this work is that: Bingham model of rheological behavior is that it doesn't represent the flow of mixed combinations of bentonites - CMC on log-log coordinates. It splits above measured data for low shear rates, it coincides with them at medium rates and match them at high rates. It match them well at higher concentrations of either bentonites or CMC. .The Ostwald model match well the flow of CMC suspensions and similarly that of mixed suspensions The Hershel-Buckley model may represent well the bentonites particularly those of high CMC concentrations. and the mixed suspensions, but I don't like because interception with the stress coordinates like Bingham model by extrapolation.

This work advice fields drilling rigs operator to circulate mud with slight rotation and sometimes to slightly pull up and down the drilling string in order to support breaking gel to reduce pumping pressures.

\section{6- References:}

1-Metzener A.B" Non-Newtonian Flow " Industrial and engineering chemistry, 1957.

2-API " The Rheology of Oil Well Drilling Fluids ",API print edition, august, 1980.

3-Kelly J. "Drilling Fluid Selection Performance and Quality Control " J. of Pet. Tech.,May 1980.

4-Gatlin C. book Petroleum Engineering "Drilling and Well Completion Practice ", 1960 Newbery,USA.

5-M. J. Crochet et al " Numerical Simulation of Non-Newtonian Flow" Elsevier, 1980.

6-Couarraze et al" Initiation a la Rheology" Is bin 2-85206-19 Lavoisier, Paris,France, 1983.

7-Shallal Aldelaimi" Surpression et Depression Dans les Annulaires des Puits Petrolierencours de laManoevr",vol.1, UTC\& IFP, France, 1991.

8-Walker R.G. book, "Drilling Fluid Rheology" Drilling, DCW, Feb.1971.

9-George R. et al, book "Composition and properties of drilling and completion fluids" Gulf,Pub.Co.,1988.

10-Moore P.L., book, "Drilling Practice Manual", Pet. Pub. Co., Tulsa, USA,1974.

11-Haak "Viscosimeter Instruction Manual "HaakMes.Technic Co., Rotovisco RV20.Germany,1988.

12-Melroz J.C. et el "A practical utilization of the theory of Bingham flow in stationary pipes and annulus" Pet. Trans., AIME vol.213, 1958. 